$\begin{array}{ll}\text { Abstracta Iranica } & \begin{array}{l}\text { Abstracta Iranica } \\ \text { Revue bibliographique pour le domaine irano-aryen }\end{array} \\ & \text { Volume } \mathbf{3 1} \mid \mathbf{2 0 1 1} \\ & \text { Comptes rendus des publications de } \mathbf{2 0 0 8}\end{array}$

\title{
« Ancient Chorasmian mural art ». BAI, 18, 2004 [2008], p. 69-95, 15 figs. dans le texte.
}

\section{Frantz Grenet}

\section{(2) OpenEdition}

1 Journals

Édition électronique

URL : http://journals.openedition.org/abstractairanica/39133

DOI : 10.4000/abstractairanica.39133

ISSN : 1961-960X

Éditeur :

CNRS (UMR 7528 Mondes iraniens et indiens), Éditions de l'IFRI

\section{Édition imprimée}

Date de publication : 15 mai 2011

ISSN : 0240-8910

Référence électronique

Frantz Grenet, « «Ancient Chorasmian mural art ». BAl, 18, 2004 [2008], p. 69-95, 15 figs. dans le texte. », Abstracta Iranica [En ligne], Volume 31 | 2011, document 25, mis en ligne le 15 février 2012. consulté le 27 septembre 2020. URL : http://journals.openedition.org/abstractairanica/39133 ; DOI : https://doi.org/10.4000/abstractairanica.39133

Ce document a été généré automatiquement le 27 septembre 2020.

Tous droits réservés 
«Ancient Chorasmian mural art ». BAI, 18, 2004 [2008], p. 69-95, 15 figs. dans le texte.

Frantz Grenet 
1 Cet article rassemble toutes les données disponibles (contextes archéologiques, styles, techniques) sur la peinture murale en Chorasmie à la période antique, depuis le palais de Kalaly-gyr 1 (daté des $\mathrm{V}^{\mathrm{e}}$-IV $\mathrm{e}$ s. av. n.è. selon la chronologie probablement trop haute de Tolstov) jusqu'aux découvertes toutes récentes de la mission karakalpakoaustralienne à Kazakli-yatkan. Cette grande forteresse fut sans doute la première capitale de la Chorasmie et son palais est en train de livrer un décor peint datant du $\mathrm{I}^{\mathrm{er}}$ s. av. n.è. (à la note 6 , corriger "C.E. » en "B.C.E. »), très riche et diversifié bien que parvenu de manière le plus souvent fragmentaire. Il s'agit notamment, dans le corridor ouest du noyau central du palais, d'une procession de chevaux menés par des personnages à pied, ainsi qu'une galerie de portraits de profil, assez stéréotypés, disposés dans des cadres carrés formant des réseaux. Ce sont évidemment des notables : plusieurs portent sur la tête l'image soit d'un oiseau, soit d'un lion, et tous ont un torque spiralé identique à celui de certains souverains arsacides du $\mathrm{I}^{\mathrm{er}} \mathrm{s}$. av. notre ère (voir F. Kidd, "Steppe elements in the art of ancient Chorasmia ", article à paraître signalé en bibliographie finale). Je fais pour ma part l'hypothèse que ces notables attendent l'audience royale (d'où le détail attesté nulle part ailleurs des oreilles colorées en rouge, destiné à suggérer la réceptivité à la parole du roi ?). L'architecture du palais, en corridors carrés emboîtés, pourrait alors avoir eu pour fonction de matérialiser le protocole concentrique des audiences royales; à la description symbolique des remparts d'Ecbatane (Hérodote 1.98) on peut ajouter celle des audiences d'Alexandre (Polyen, Stratagemata 4.24 ; Athénée, Deipnosophistes 12.539).

2 Le seul autre site examiné ici à avoir livré un fragment figuré est Koj-Krylgan-kala (image d'un archer, qui pourrait provenir de l'étage supérieur du bâtiment central et, en ce cas, remonter à la première construction vers le $\mathrm{II}^{\mathrm{e}} \mathrm{s}$. av. n.è.; sur les problèmes de chronologie et de fonction du monument voir Abs. Ir. 28, c.r. $n^{\circ} 60$ ).

\section{INDEX}

Thèmes : 3.1. Est de l'Iran

\section{AUTEURS}

FRANTZ GRENET

CNRS - EPHE - Paris 